\title{
Reseña de tesis doctoral: FACTORES DE INFLUENCIA EN EL CONSUMO DE TURISMO. ANÁLISIS DEL DESTINO TURÍSTICO: RIBEIRA SACRA
}

\author{
Director \\ Dr. José Antonio Fraiz Brea Doctorando \\ Roberto Carballo Meiriño \\ https://doi.org/10.17979/redma.2010.01.05.4716
}

\section{RESUMEN:}

La tesis doctoral surge a partir de la necesidad de contribuir al desarrollo de alternativas económicas en los espacios rurales en el interior de España. Los objetivos son: desarrollar una visión global de la fidelidad de los consumidores en el ámbito de los destinos turísticos; identificar segmentos diferenciados de visitantes y medir la percepción de los visitantes sobre la calidad de los servicios proporcionados en la zona de la Ribeira Sacra. Entre sus conclusiones señala que la satisfacción de los consumidores con un destino turístico se encuentra determinada por la calidad prestada por las empresas del sector pero también por otros factores como la adecuada señalización, la conservación del patrimonio o la hospitalidad de la población local.

Palabras clave: turismo, alternativas económicas, influencia, consumo

\section{ABSTRACT}

PhD THESIS REVIEW: INFLUENCE FACTORS IN TOURISM. ANALYSIS OF THE TOURISM DESTINATION RIBEIRA SACRA 
The doctoral thesis merges from the necessity of contributing to the development of economic alternatives in the rural spaces in Spain. The objectives are: develop a global vision of the consumers' fidelity in tourism, identifying different visitors types and seizing the perception of visitors over the quality of services in the Ribeira Sacra. Among the conclusions the text highlights that the satisfaction of a consumer with a tourism destiny is determined by the quality given by the companies, but also other factors such as qualified signalization, conservation and local population's hospitality.

Keywords: tourism, economic alternatives, influence, consumption 


\section{JUSTIFICACIÓN DE LA INVESTIGACIÓN}

La investigación, centrada en un destino turístico interior, surge de la necesidad de contribuir al desarrollo de alternativas económicas en los espacios rurales.

Desde la perspectiva de las tendencias de la demanda, los consumidores han evolucionado hacia un mayor interés por el medio ambiente y por la búsqueda de productos individualizados. Esto supone una oportunidad para aquellos territorios dotados de especial riqueza natural y patrimonial.

Paralelamente, se ha producido una intensificación de la competencia por la atracción de visitantes, lo que pone de relieve la importancia de generar una experiencia satisfactoria.

Además, la oferta turística debe adaptarse a las necesidades de los consumidores, lo que nos lleva a analizar los factores que motivan las decisiones de consumo.

\section{OBJETIVOS DE LA INVESTIGACIÓN}

Con este trabajo pretendemos lograr tres objetivos:

- El primero es desarrollar una visión global de la fidelidad de los consumidores en el ámbito de los destinos turísticos. Para ello, se han analizado, con un enfoque teórico y empírico, las relaciones causales entre las motivaciones de viaje, la satisfacción con características específicas del destino, la evaluación global de la estancia y la fidelidad (caracterizada esta última por la intención de recomendar la zona y de regresar en el futuro). Todas las relaciones 
planteadas se contrastaron conjuntamente mediante una aproximación basada en la modelización con ecuaciones estructurales.

- El segundo objetivo consiste en identificar segmentos diferenciados de visitantes, en base a sus motivaciones de viaje; describiendo el perfil de cada grupo.

- El último objetivo consistió en medir la percepción de los visitantes sobre la calidad de los servicios proporcionados por las empresas del sector y sobre otros recursos de la Ribeira Sacra (que abarca municipios de las provincias de Lugo y Ourense). Es decir, se realizó un diagnóstico o evaluación del destino turístico desde la perspectiva de los visitantes. Dicha evaluación se ha basado en la metodología de Análisis Importancia - Desempeño (ImportancePerformance Análisis), que consiste en analizar conjuntamente la importancia que los usuarios conceden a los atributos o elementos que componen un producto o servicio y su valoración tras haberlo comprado o experimentado.

\section{ESTRUCTURA DEL TRABAJO}

La investigación se estructura en cinco capítulos:

- El primero analiza la posibilidad de aplicar técnicas comerciales en el ámbito de los territorios. También se describe el área geográfica objeto de análisis.

- El segundo capítulo plantea el marco teórico, que iniciamos con una aproximación al concepto de destino turístico. A continuación, se tratan aspectos que se han relacionado tradicionalmente con la fidelidad de los consumidores.

- En el capítulo tercero se propone un modelo sobre el proceso de formación de la fidelidad hacia un destino turístico y se formulan ciertas hipótesis.

- Los resultados empíricos se presentan en el capítulo cuarto.

- El trabajo finaliza con la exposición de las conclusiones. 


\section{ÁREA GEOGRÁFICA ANALIZADA: RIBEIRA SACRA}

La "Ribeira Sacra" abarca municipios de Lugo y Ourense; destacando por su atractivo paisajístico y patrimonial.

Es una zona esencialmente rural muy afectada por la pérdida de población, que se ha reducido más de un $10 \%$ en la última década, como vemos en el gráfico.

También existe un claro proceso de envejecimiento, ya que, más de un tercio de los habitantes supera los 64 años.

Sólo un 6\% de la población activa trabaja en hostelería; lo que resulta indicativo de que el turismo aún presenta un peso reducido en el tejido productivo de la zona.

\section{CONCLUSIONES}

La satisfacción de los consumidores con un destino turístico se encuentra determinada por múltiples agentes. La calidad prestada por las empresas del sector constituye una condición necesaria; que debe complementarse con otros factores como la adecuada señalización, la conservación del patrimonio o la hospitalidad de la población local.

Esto implica, que el desarrollo de un destino no es posible por el buen funcionamiento aislado de un único agente; sino que requiere de una actuación coordinada entre el ámbito privado, el sector público y la comunidad local en su conjunto. 
Por otra parte, la experiencia turística puede concebirse como un proceso de creación de valor en el que participan activamente los propios visitantes.

El trabajo empírico ha puesto de manifiesto la existencia de relaciones entre las motivaciones turísticas y los procesos de evaluación de la experiencia de consumo. Por tanto, la oferta debe adaptarse a las principales motivaciones de los visitantes.

Por último, conviene resaltar que el mercado no puede entenderse como un todo homogéneo. Es posible identificar grupos de consumidores diferenciados en función de sus motivaciones; lo que pone de relieve la necesidad de desarrollar estrategias orientadas a los segmentos objetivo.

\section{IMPLICACIONES DE GESTIÓN}

Atendiendo a aspectos más concretos, observamos que los visitantes que desconocían la zona se perdían con frecuencia. Por lo que conviene avanzar hacia una estrategia global de señalización, con indicaciones que resalten el acceso directo a ciertos núcleos, desde los que guiar al visitante a rutas o enclaves turísticos concretos.

Además, resulta escasa la dotación de paneles interpretativos e información sobre la posibilidad de visita en algunos monumentos; aunque se valora positivamente la entrada gratuita.

También es importante la señalización de las rutas de senderismo, pero debe complementarse con labores de mantenimiento, dado el rápido crecimiento de la vegetación.

Otro aspecto a mejorar se refiere a la escasez de opciones para los niños. Se percibe una demanda de algún tipo de infraestructura de ocio orientada a toda 
la familia; que contribuiría a atraer y a alargar la estancia de este segmento de turistas.

Por último, mencionar la necesidad de organizar más actividades para los visitantes; tratando de ofrecer productos integrados. Conviene destacar que la existencia de elementos atractivos no es suficiente, cuando estos se perciben como dispersos y poco cohesionados.

\section{Para citar este artículo:}

Fraiz Brea, José Antonio - Carballo Meiriño, Roberto (17-12-2010). Reseña de tesis doctoral: FACTORES DE INFLUENCIA EN EL CONSUMO DE TURISMO. ANÁLISIS DEL DESTINO TURÍSTICO: RIBEIRA SACRA.

REDMARKA - CIECID - Unidad de Investigaci $\tilde{A}^{3} n$ en Marketing Aplicado-Universidad de A CoruÃ $\pm a$ Año II, Número 5, V1, pp.95-101

ISSN 1852-2300

URL del Documento : cienciared.com.ar/ra/doc.php?n=1416

URL de la Revista : cienciared.com.ar/ra/revista.php?wid=39 